\title{
EDUCAÇÃO PERMANENTE EM SAÚDE E MODELO ASSISTENCIAL: correlações no cotidiano de serviço na Atenção Primária à Saúde
}

Kátia Ferreira Costa Campos, Rita de Cássia Marques, Ricardo Burg Ceccim, Kênia Lara Silva

\section{RESUMO}

Motivação: No Brasil, para a qualificação profissional em um modelo que atenda às necessidades de saúde dos usuários, fez-se uma aposta na Educação Permanente em Saúde (EPS). Pretendeu-se, a partir da análise do cotidiano de uma Unidade Básica de Saúde (UBS), responder quais as correlações da EPS com as mudanças no modelo assistencial. Nesse sentido, o objetivo geral foi analisar o cotidiano de serviço na UBS, identificando mudanças na atenção ao usuário, proporcionadas pela EPS.

Método: O cenário foi uma unidade básica de saúde do município de Belo Horizonte. Os participantes foram os trabalhadores e os usuários da unidade. 0 referencial de análise foi a abordagem do cotidiano de Agnes Heller. Os dados foram submetidos à análise crítica de discurso. Foram realizadas $\mathbf{3 0}$ entrevistas em profundidade, $\mathbf{2 5}$ com trabalhadores e 05 com usuários, resultando num total de $22 \mathrm{~h}$ de entrevistas.

Resultados: Os resultados evidenciaram forças potenciais dos trabalhadores e usuários, para colaborar na mudança de modelo assistencial, revelando a busca pela centralidade dos usuários na coordenação da atenção à saúde e a priorização das tecnologias leves nas práticas de cuidado.

Conclusões: Concluiu-se que são necessários mais investimentos nos processos de educação permanente em saúde e que o reconhecimento do cotidiano como espaço para reflexões e análises é capaz de provocar desacomodação e superação crítica, abrindo espaço para novas práticas sociais e de cuidado na Atenção Primária à Saúde.

Palavras-chave: Educação Permanente em Saúde. Modelo assistencial. Atenção Primária à Saúde.

Revista da Rede APS 2019 Publicada em: $24 / 07 / 2019$

DOI:10.14295/aps.v1i2.28

Kátia Ferreira Costa Campos (Escola de Enfermagem da UFMG, Brasil); Rita de Cássia Marques (Escola de Enfermagem da UFMG, Brasil); Ricardo Burg Ceccim (Faculdade de Educação da UFRGS, Brasil); Kênia Lara Silva (Escola de Enfermagem da UFMG, Brasil);

Correspondência para: Kátia Ferreira Costa Campos, katiacostacamposenf@g mail.com 
Vol. 1, n. 2, p. 132/140 | Maio/Agosto - 2019

ISSN 2596-3317 - DOI 10.14295/aps.v1i2.28

Campos, K. F. C.; Marques, R. C.; Ceccim, R. B.; Silva, K.L.

\section{INTRODUÇÃO}

Compreende-se como modelo assistencial o modo como são organizadas e produzidas as intervenções em saúde, envolvendo a relação entre trabalhadores e usuários ou entre trabalhadores e população mediada pela combinação das diversas tecnologias, incluindo as relações humanas nos processos de trabalho, para atender às demandas e necessidades sociais em saúde. Nesse processo, deve-se levar em conta o cotidiano das práticas assistenciais e os processos de determinação ou condicionamento social para a definição do desenho assistencial, centrando no encontro e práticas cuidadoras com o usuário, direcionado para a melhora na qualidade de vida e bem-estar, levando-se em conta a sua dignidade, direitos, diversidade, interesses e participação efetiva (CECCIM, 1999; PAIM, 2012).

Ao longo da trajetória de conformação de um modelo assistencial no Brasil, que atendesse às necessidades sociais em saúde, fez-se uma aposta na Educação Permanente em Saúde como estratégia para as mudanças necessárias, pois se buscava que os profissionais pudessem ser capazes de atuar criticamente em relação à realidade, transformando-a (HADDAD; ROSCHKE; DAVINI, 1994; BRASIL, 2004). Dessa forma, considera-se que, para a organização do cuidado na Atenção Primária à Saúde (APS) como porta preferencial, se deve dar importância à educação permanente produzida no cotidiano de serviço, valorizando a experiência e os saberes em trocas no dia a dia, podendo assim construir novas formas de interação entre serviço e população, entre trabalhador e usuário.

No âmbito apresentado, pretendeu-se responder no estudo, a partir da análise do cotidiano de uma Unidade Básica de Saúde (UBS), quais as correlações da Educação Permanente em Saúde (EPS) com as mudanças no modelo assistencial. Nesse sentido, o objetivo geral foi analisar o cotidiano do serviço na UBS identificando mudanças na atenção ao usuário, proporcionadas pela EPS.

\section{Metodologia}

Trata-se de um estudo qualitativo ancorado na teoria do cotidiano de Agnes Heller, desenvolvido em uma unidade básica de saúde da cidade de Belo Horizonte, capital do Estado de Minas Gerais. Foi utilizada a entrevista em profundidade, num total de 30 entrevistados, somando $22 \mathrm{~h}$ de duração. Foram entrevistados 25 trabalhadores de saúde (T) e 05 usuários (U). Dentre os trabalhadores, 4 médicos, 1 enfermeiro, 2 profissionais do Núcleo de Apoio Saúde da Família/Atenção Básica (NASF), 8 técnicos em enfermagem, 8 Agentes Comunitários de Saúde (ACS), 1 Agente de Combate às Endemias (ACE) e gerente. Foram realizadas entrevistas com representantes dos usuários no Conselho Local de Saúde. Para as Codificações $T$ ou $U$ usou-se a sequência numérica a partir de 1 .

As entrevistas contemplaram a relação de como acontece, no olhar dos trabalhadores de saúde e dos usuários, mudanças na atenção correlacionadas à EPS. A análise foi mediada pela análise crítica de discurso proposta por FAIRCLOUGH (2016), nas dimensões do texto, da prática social e da prática discursiva.

O projeto, do qual este artigo é um dos produtos, foi submetido ao Comitê de Ética da Universidade Federal de Minas Gerais (UFMG), com anuência da Secretaria Municipal de Saúde de Belo Horizonte (SMS-BH). Em todas as etapas do estudo foram atendidas as orientações da Resolução $n^{\circ}$ $466 / 2012$.

\section{RESULTADOS}

Mudanças nos modos de assistir os usuários foram abstraídas nos enunciados dos trabalhadores e dos usuários, revelando correlações positivas dos processos de EPS no cotidiano dos serviços na UBS, destacando-se aproximações e distanciamentos da centralidade do usuário na atenção, assim como a priorização de tecnologias leves ou relacionais.

Os trabalhadores da UBS, ao serem perguntados sobre as mudanças proporcionadas pela EPS, 


\section{APS em Revista}

Vol. 1, n. 2, p. 132/140 | Maio/Agosto - 2019

ISSN 2596-3317 - DOI 10.14295/aps.v1i2.28

Campos, K. F. C.; Marques, R. C.; Ceccim, R. B.; Silva, K.L.

detectaram aquelas voltadas para a ampliação da atenção ao usuário, dando-Ihes centralidade.

A atenção pro usuário aumenta, né? Fica mais atento àquela pessoa. Você consegue trazer ela pro centro da saúde. [...] Você vai atrás, conversa e consegue trazer a pessoa e criar um vínculo com ela, né? [...] Depende do tipo do paciente, né? [...] Cada um é de uma forma. Saúde mental é mais difícil. [...] Aí tem que ir andando aos pouquinhos, né? Deixar fazer, deixar o limite dele, né? Até conseguir (T6).

O enunciado de T6 vincula o efeito positivo da EPS na atenção ao usuário ao fato de se importarem com ele(a), preocupando-se com a criação de vínculo, respeitando seus limites e sua condição de entendimento, considerando que "cada um é um", demonstrando que a diminuição da verticalidade na interação entre trabalhadores e usuários, com encontros que se dão pelo respeito ao tempo e discurso do usuário, é favorável à mudança no modelo assistencial, podendo-se caracterizar forças potenciais intrínsecas a cada ator em relação, que devem ser exploradas nas interações.

Para Ayres (2004), o trabalho em saúde reclama "encontro" entre os atores em relação, podendo esse encontro se configurar de várias formas, desde a impessoalidade até a busca de reconhecimento mútuo, numa relação dialógica.

O enunciante T10 fala sobre o tratamento da tuberculose (TB) e sua necessidade de conhecer a realidade dos usuários, colocando o trabalho como fonte de aprendizado.

[...] aí nós discutimos sobre TB, como que chama [pro tratamento], pra chamar os acompanhantes... pra chamar os... [...] os comunicantes, os contatos todos... como que faz pra ter o tratamento... então, isso tudo, toda a equipe tem que saber. [...], mas quando tem casos, [...].... tem que ficar bem perto. Então aí o ganho é inclusive do agente comunitário que não é formado na área de saúde, tem treinamentos... ele aprende mesmo sobre doença. $E$ isso é mais fácil dele poder captar outros casos, que eu acho que fica mais fácil pra eles. E eles trazem (T10).

A necessidade de conhecer o usuário nos seus hábitos e costumes, que vão determinar o uso correto da medicação, integra as práticas da Estratégia Saúde da Família (ESF), com acompanhamento individualizado pelo Agente Comunitário de Saúde. Numa relação de interfaces, é evidenciada a necessidade de aprender para oferecer a melhor assistência, reconhecendo a indissociabilidade da relação trabalho-aprendizado.

Merhy (2014) confirma que o trabalho proporciona aprendizado, produção do conhecimento e saída do território da imobilidade na complexidade do cotidiano do trabalho em saúde. Ceccim; Ferla (2008) acrescentam que o trabalho ser considerado como fonte de aprendizado é uma premissa da educação permanente em saúde.

Os usuários discorrem sobre ações voltadas para a melhoria do acesso, destacando a centralidade em consultas médicas, exames e medicamentos, demonstrando expectativas de melhorias na atenção, conforme prioridade, tempos de resposta relacionada a exames e consultas especializadas.

Melhorou, mas tem que melhorar muito ainda, porque exame às vezes demora muito e às vezes também pra marcar um médico também demora muito ainda, então tem que melhorar bastante, tem muuuito o que melhorar (U5).

Demora, mas atende, né? Mas aqui, sobre tratamento ninguém tem o que reclamar não, todo mundo trata bem! Mas só o que demora são as consultas que a gente faz, demora três meses pra poder consultar [refere-se a consultas especializadas] (risos) (U4)

Os enunciados demonstram que o modelo voltado às necessidades sociais em saúde, focado na saúde como qualidade de vida, não prescinde da atenção de necessidades médicas, mas as mudanças no 
modelo médico-centrado podem ser mediadas pelo conhecimento e reflexão do ACS. As dificuldades para as consultas de referência especializada precisam ser sandas, mas o usuário também precisa rever sua posição quanto à utilização das consultas especializadas.

[...] pra alguns, que a gente tem acesso, que consegue entender as coisas, eu tô achando que tem melhorado. A gente teve uma baixa de perda de consultas (?), então [...]a gente tá conseguindo conscientizar eles da dificuldade que é quando se perde uma consulta. [...] Eles estão valorizando essa questão de saúde (T2).

A ACS atribui mudança nos usuários e as relaciona às suas práticas de educação, que podem provocar desacomodação. Dessa maneira, conforma-se uma prática voltada não somente para o individual, mas também para o coletivo de usuários, os territórios e as formas de viver.

A centralidade nos usuários, como aqueles que gastam sua vida de certos modos e não de outros, que usam sua capacidade de viver para produzir modos de caminhar na vida, [nos leva a entender] a saúde [como] possibilidade de criar [...] mecanismos de gastar [no sentido de usufruir] a potência de viver, logo, [os usuários são os] produtores e portadores das necessidades de saúde (MERHY, 2002, p. 3).

No estudo pode ser registrada, pelos discursos dos trabalhadores, a priorização tecnológica praticada por eles. Rememora-se que na combinação de tecnologias, para as práticas de saúde, a priorização de tecnologias leves é considerada como indicativo de mudança de modelo assistencial.

Acerca das tecnologias priorizadas na atenção à saúde, aporta-se na abordagem de Merhy (2002), que nomeia como "tecnologias leves" aquelas que envolvem o encontro e as trocas, favorecendo a ressignificação dos atos; como "leve-duras" aquelas constituídas pelos saberes estruturados (protocolos e diretrizes fechadas); e como "duras" aquelas que são relacionadas aos equipamentos, instrumentos e aparelhos. A combinação entre elas pode produzir trabalho vivo ou reproduzir trabalho morto. O trabalho vivo é aquele em que se questionam os sentidos e se valorizam as relações, os encontros, negociações, que aguçam a criatividade e a reinvenção do fazer em saúde. O trabalho morto é aquele em que se privilegia somente os saberes prévios ao encontro e o uso da tecnologia dura para as práticas de saúde.

Ao serem indagados pelas mudanças proporcionadas pela EPS no cotidiano de serviço, os trabalhadores, também, associam-nas ao processo vivenciado de discussão de mudanças no protocolo de atendimento à demanda espontânea. $E$ demonstraram que valorizam 0 uso das tecnologias leves, embora ainda presos aos horários do protocolo criado.

A gente tem que dar um atendimento qualificado pras pessoas e não sentar pra um curativinho, manda embora... uma coisa que você não vai resolver o problema, né? [...] agora mesmo eu discuti ali com as meninas, de um familiar vir marcar pro outro, eu acho que gente não pode tirar essa possibilidade, porque às vezes a pessoa trabalha, né? Então assim... são coisas que só no funcionamento, que vão aparecendo os questionamentos então a gente tem que ir aparando as arestas. [...] Porque a gente trouxe uma organização, mas toda organização... ela é um pouco limitadora, né? [...] Hoje a gente tá tentando fazer uma escuta mais qualificada, mas tem que ir em horário específico... então alguns ficam bravos com a gente [...] (T9).

O enunciado de T9 informa nova organização do processo de trabalho, com questionamentos acerca do sentido de algumas decisões, demonstrando que a escuta deve ser mais valorizada que o protocolo.

Os trabalhadores valorizam a experiência, o conhecimento, o trabalho em equipe e os protocolos, em um julgamento positivo sobre a contribuição para a organização do processo de 
trabalho, repercutindo na melhora de resultados da atenção à saúde aos usuários.

[...] eu vejo uma mudança enorme [...] porque a gente não dá conta de atender à demanda toda através de consulta médica, né... se não tiver uma organização nas agendas de atendimento, de grupos, grupos operativos de atendimento compartilhado, de atendimento de enfermagem, né, não dá conta, e dos profissionais da equipe também, né... quanto mais trabalha unido, a atenção é qualificada, né, melhores são os resultados, entendeu?...então eu vejo isso como fundamental (T13).

[...] se a pessoa tem alguma dúvida vai na minha casa, pergunta, né? Então assim, eu não nego de atender, não nego de responder e mesmo que também de outras equipes, né? Assim você tem que sempre estar aberta, né? Pra poder resolver na medida do possível que você dá. Se não der conta, se chegou um ponto que você não dá conta então... procurar e encaminhar pra outras instâncias (T23).

Na combinação de tecnologias, fica claro que há forte presença de tecnologias leves, mas com predominância de tecnologias leve-duras, dada a valorização dos protocolos, mesmo que adaptados à realidade. Dessa forma, os trabalhadores operam as tecnologias em uma predominância da visão tecnicista do trabalho, mesmo sendo visível o trabalho criativo.

Sobre o trabalho criativo, Heller (2002; 2014) assegura que só é evidenciado quando há objetivações para-si, que faz com que o homem se torne consciente do "eu" e do "nós", despertado pelos atributos do ser social pelo trabalho, sociabilidade, universalidade e liberdade. Assim, existe a possibilidade de experimentação de superação em direção ao não cotidiano, retornando ao cotidiano com um olhar diferenciado para a realidade que o rodeia.

Assim, a superação do cotidiano se dá a partir de um si em relação, experiência de aprendizado e mudanças, sem necessariamente um processo ensino-aprendizagem, programado e vertical. Cardoso (2012) defende que nem sempre é necessária uma atividade educacional programada e defende a necessidade de proporcionar oportunidades para o desenvolvimento dos trabalhadores para alcançar mudanças e qualificação na atenção à saúde.

Os usuários, quando indagados pelas mudanças percebidas no serviço de saúde da UBS, da mesma forma demonstraram que houve mudanças positivas, indicando melhorias de acesso na atenção aos usuários, contudo, demonstram, também, valorização da atenção centrada no médico da área de abrangência.

[...] eu acho que, igual aqui na vila, melhorou. A gente tem o médico, [...] melhorou porque ficou mais perto pra gente né? [...] a gente teria que às vezes ir pra sede, às vezes a gente não tem condição de estar indo de ônibus... eu acho que isso tudo foi bom pra vila. Foi bacana, inclusive em processos dele, em assistência médica melhorou muito pra nós. Foi muito importante. [...] Os ACS eles mudaram a maneira de trabalhar, apesar das dificuldades deles, eles permanecem firmes e fortes. Geralmente, isso deve ser por causa da atenção deles com o ser humano, não por causa do trabalho. (U5).

É possível perceber um antes e um depois a partir da reorganização de um local para atendimento de mais fácil acesso aos usuários. No entanto, o foco está na consulta médica, quando o médico tem pertencimento ao lugar e forte vínculo com os usuários, tanto que é chamado de "nosso médico", embora se reconheça o trabalho do ACS.

Duas análises são relevantes. A primeira diz respeito ao vínculo com a comunidade e a segunda à necessidade de fortalecer o trabalho interprofissional. A equipe precisa se movimentar para construir uma atenção compartilhada, abrindo-se para o envolvimento com a comunidade dentro e fora dos muros institucionais. A esse respeito há de se aprofundar 
o conhecimento sobre trabalho colaborativo interprofissional na compreensão acerca da participação e reconhecimento dos trabalhadores como integrantes da equipe multiprofissional de saúde.

O acesso do usuário à informação consistente e de forma clara também é descrita pelos trabalhadores da UBS.

Porque todo mundo tá falando a mesma coisa, se eu falo a mesma coisa, o técnico fala, o enfermeiro fala, o assistente social, né? Todos os profissionais, né? Então, de uma certa forma, ele também começa a perceber que a fala é uma só, que não é a opinião de um ou a opinião de outro, é um consenso. E acho que com isso a gente consegue que ele também incorpore essa informação, [...] ... o cuidado com ele é um cuidado melhor (T12).

A valorização da construção coletiva, apresentada por T12, a ser oferecida ao usuário como um consenso, contribui para melhor usufruto do serviço de saúde. A convergência de discursos e seus horizontes é uma necessidade nos modos de operar e gerir a assistência à saúde oferecida a indivíduos e coletivos (AYRES, 2004). Tais convergências requisitam enfrentamentos e superações em busca de transformações de si mesmo e de seu meio. Heller (2002) reconhece que o homem, ao enfrentar a realidade, experimenta a superação e vê os demais que vivenciam a realidade, pela educação, se tornarem representantes do mundo onde estão inseridos.

Dessa forma, afirma-se que a educação permanente em saúde é potencial para a mudança, com necessidade de investimentos tanto nos trabalhadores como nos usuários e parcerias possíveis, na assistência à saúde, para que todos compreendam o modelo assistencial praticado e as mudanças que precisam ocorrer.

O acolhimento, como tecnologia leve, é reconhecido pelos trabalhadores quando mencionam mudanças na forma como lançam o olhar ao usuário nos atendimentos relacionados ao acolhimento da demanda espontânea, manifestando ampliação da visão para além das necessidades que geraram a demanda à unidade.

Muda a nossa perspectiva, igual assim... é, a nossa abordagem em relação ao paciente, a nossa busca mesmo. Às vezes eu tô atendendo um paciente no acolhimento... Aí a gente já tem um outro olhar... Olha, deixa eu ver o cartão de vacina, né? Sua mãe já tomou vacina? Seu pai, que a gente conhece a família, né? Ah, fulana de tal tá grávida, lá na sua casa, já tomou as vacinas da gravidez? Então, assim, a gente tem tido esse cuidado maior, tem tido outra visão (T22).

O uso do termo "nosso", "nossa", "a gente" indica que a mudança é atribuída a um conjunto dos trabalhadores. Nota-se que a mudança envolve uma perspectiva para além da tecnicista e pragmática no trabalho em saúde.

Os usuários indicam que o acolhimento é condição necessária na atenção a eles e que houve melhoras nesse sentido, apesar de, em meio às melhorias, ainda estar presente o problema de coerência entre os trabalhadores, acerca das informações dadas ao usuário.

[...]. Todos têm que ter uma forma de acolher e receber o usuário quando ele chega [na] saúde procurando uma informação. [...] Eu acho até que melhorou um pouco, desde que eu uso, pelo tempo que eu uso, hoje o atendimento, o acolhimento, pra mim, eu acho melhor. [...] Às vezes você ainda tem alguma dificuldade, você tem uma informação de um, aí quando você chega ele te dá outra informação que elas não batem, não contam. Mas sempre, de uns anos pra cá, eu achei que melhorou bastante essa informação. (U4)

Os usuários também criticam a forma de acolhimento utilizada, muitas vezes, como obstáculo. 
Que às vezes cê chega no posto, cê já sai da sala da médica com o papel agendado... o dia da outra consulta. Aí tem esse tal de Colhimento. Cê tem que passar no Colhimento... explicar o que que cê tem pra você poder tá agendando com a médica de novo? Até pegar um resultado de exame... (U3).

De forma declarativa e interrogativa, o usuário indica insatisfação na organização do processo de trabalho. O acolhimento como tecnologia das relações deve servir à escuta qualificada ao usuário, para que de forma oportuna e resolutiva seja solucionado seu problema (MERHY, FEUERWERKER, CECCIM, 2006).

A centralidade no encontro com o usuário pressupõe uma perspectiva ampliada do cuidado, com reconhecimento da necessidade de atuação dos trabalhadores de saúde de modo a contemplar as múltiplas dimensões presentes nas necessidades de saúde (MERHY, 2002).

Para um modelo assistencial que tem como premissa a centralidade no encontro, a atenção primária precisa se reorganizar, ampliando seu escopo de conhecimentos e práticas com configurações de equipes e novos processos de trabalho marcados pela vinculação ao exercício da cidadania, que favoreça a qualidade da relação interpessoal, o cotidiano das práticas assistenciais com orientação para a integralidade e as necessidades ampliadas de saúde, em sintonia com os princípios do Sistema Único de Saúde (FERTONINI, 2010; FERTONINI et al., 2015).

Nesse sentido, urge a superação dos modelos centrados em interesses corporativos profissionais ou econômico-financeiros, transformando-os em modelos centrados nas necessidades sociais em saúde, com superação da lógica de produção de procedimentos em si, por uma produção em defesa da vida, individual e coletiva, sendo necessário construir novos sentidos para as ações de saúde.

Nessa nova forma de produção, estão os trabalhadores de saúde, que podem produzir novos sentidos e se colocarem como "fazedores de atos de saúde" e se apresentarem como tal para negociar o modelo assistencial, com reconhecimento e legitimação para a atuação e a busca da negociação dos modos de fazer saúde, com foco nas necessidades trazidas pelos usuários, que consideram a saúde como um valor de uso fundamental para a possibilidade de produzir sua vida (MEHRY, 2002; 2015).

A visão do usuário, seja pelo trabalhador de saúde, seja pela gestão, deve ser a de que o usuário não se perceba como mais um cliente em busca de consumo de serviços e procedimentos na saúde. 0 papel deve ser ampliado para a consideração do usuário a partir de sua realidade e seus percursos, devendo-se problematizar suas escolhas também como protagonista na assistência à saúde (ALMEIDA LIMA et al., 2014).

Para as mudanças em direção à consolidação do modelo assistencial idealizado para o Sistema Único de Saúde (SUS), há de se considerar os sujeitos em ação na UBS. Estes produzem EPS e contribuem para a mudança de modelo, no fazer em ato, que pode levar à centralidade do encontro e priorização de tecnologias leves, no cotidiano de serviço.

\section{CONSIDERAÇÕES FINAIS}

Não se pode afirmar que houve mudança de modelo assistencial requerido pelo SUS, mas sim aproximações positivas, sobressaindo a priorização de tecnologias leves e centralização do usuário.

Ficou evidente a necessidade de mais investimentos para que a EPS, produzida no cotidiano da APS, se mostre reconhecida como potencial para provocar mudanças e crescimento tanto dos trabalhadores como de usuários, buscando na organização da atenção na APS, estratégias que provoquem valorização da experiência e saberes, interações e trocas no dia a dia, que buscam captar e entender as necessidades de saúde dos usuários.

A visão biologicista, centrada na perspectiva médica, precisa sair de cena e a EPS se colocar 


\section{APS em Revista}

Vol. 1, n. 2, p. 132/140 | Maio/Agosto - 2019

ISSN 2596-3317 - DOI 10.14295/aps.v1i2.28

Campos, K. F. C.; Marques, R. C.; Ceccim, R. B.; Silva, K.L.

como força potencial para provocar a ampliação do olhar, requerendo o protagonismo dos seres em relação, num círculo de novas reflexões, novas mudanças voltadas para o modelo que melhor combine promoção da saúde, prevenção e tratamento de doenças e agravos, e recuperação da saúde, associado à EPS como dispositivo cotidiano que produz protagonismo dos seres em relação, uma relação corresponsável como mote de atuação da equipe e constante revisão das práticas, seja pelo confronto com a experiência coletiva local, seja com a literatura, em perder a dimensão de escuta ativa dos usuários.

\section{REFERÊNCIAS BIBLIOGRÁFICAS}

(1) ALMEIDA LIMA, C. et al. Relação profissionalusuário de saúde da família: perspectiva da bioética contratualista. Rev Bioét (Impr.), v. 22, n. 1, p. 15260, 2014.

(2) AYRES, J.R.C.M. O cuidado, os modos de ser (do) humano e as práticas de saúde. Saúde Soc, São Paulo, v. 13, n. 3, p. 16-29. 2004.

(3) BRASIL. Ministério da Saúde. Portaria 198/GM MS, de 13 de fevereiro de 2004. Institui a Política Nacional de Educação Permanente em Saúde como estratégia do Sistema Único de Saúde para a formação e o desenvolvimento de trabalhadores para o setor e dá outras providências. Brasília: MS, 2004.

(4) CARDOSO, M.C. "Rodas de educação permanente" na atenção básica de saúde: analisando contribuições. Saude Soc, São Paulo, v. 21, (Suppl.1), p. 18-28, 2012.

(5) CECCIM, Ricardo Burg. Diversidade e adversidade na prática da atenção à saúde. Saúde Revista do Nipesc, Porto Alegre - RS, v. 3, n.4, p. 5977, 1999.

(6) CECCIM, R.B.; FERLA, A.A. Educação e saúde: ensino e cidadania como travessia de fronteiras. Trab Educ Saúde, Rio de Janeiro, v. 6, n. 3, p. 443456, 2008.
(7) FAIRCLOUGH, N. Discurso e mudança social. 2. ed. Brasília: Universidade de Brasília, 2016.

(8) FERTONANI, H.P et al. Health care model: concepts and challenges for primary health care in Brazil. Ciênc \& Saúde Coletiva, v. 20, n. 6, p. 18691878, 2015.

(9) FERTONANI, H.P. Desafios de um modelo assistencial em defesa da vida, da saúde e da segurança: o que dizem os usuários da atenção básica. Tese (Doutorado em Enfermagem) - UFSC, Florianópolis, 2010.

(10) HADDAD, J.Q.; ROSCHKE, M.A.C.; DAVINI, M.C. Elementos para el análisis y la caracterización del contexto en que se dan los procesos educativos en los servicios de salud. Tendencias y perspectivas. In: HADDAD, J.Q.; ROSCHKE, M.A.C.; DAVINI, M.C. Educación permanente del personal de salud. Washington (DC): Organización Panamericana de Salud, 1994, p. 1-30,.

(11) HELLER, A. Sociologia de la vida cotidiana. Barcelona: Ediciones Península. 2. ed., 2002.

(12) HELLER. A. O cotidiano e a história. Rio de Janeiro: Paz e terra, 2014.

(13) MERHY, E.E. Educação permanente em movimento: uma política de reconhecimento e cooperação, ativando os encontros do cotidiano no mundo do trabalho em saúde, questões para os gestores, trabalhadores e quem mais quiser se ver nisso. Saúde em Redes, v. 1, n. 1, p. 07-14, 2014.

(14) MERHY, E.E; FEUERWERKER, L.C.M.; CECCIM, R.B. Educación Permanente en Salud. Salud Colectiva, v. 2, p. 147-160, 2006.

(15) PAIM, G. Modelos de atenção à saúde no Brasil. In: GIOVANELA, L. et al. Políticas e Sistema de Saúde no Brasil. Rio de Janeiro: Fiocruz, 2012. 


\section{ABSTRACT}

Background: In Brazil, for professional qualification in a model that meets the health needs of users, a commitment was made to the Permanent Education in Health (EPS). Based on the daily analysis of a Basic Health Unit (UBS), it was intended to answer the correlations between EPS and changes in the care model. In this sense, the general objective was to analyze the daily service in UBS, identifying changes in user attention, provided by EPS.

Methods: The scenario was a basic health unit of the municipality of Belo Horizonte. Participants were the workers and users of the unit. The analytical framework was Agnes Heller's daily approach. The data were submitted to critical discourse analysis. There were 30 in-depth interviews, 25 with employees and 05 with users. Resulting in a total of 22 hours of interviews.

Results: The results showed potential forces of workers and users to collaborate in the change of care model, revealing the search for the centrality of users in the coordination of health care and the prioritization of light technologies in care practices.

Conclusions: It was concluded that more investments are needed in the processes of permanent education in health and that the recognition of daily life as a space for reflection and analysis is capable of provoking disarticulation and critical overcoming, opening space for new social practices and care in Primary Care the health.

Keywords: Permanent Education in Health. Healthcare model. Primary Health Care. 